\title{
Amadeus
}

International Multidisciplinary Journal ISSSN 2525-8281

DOI: $10.14295 / a i m j . v 4 i 8.99$

\section{Hirschsprung's Disease in a young adult and its treatment with Videolaparoscopy Aid: Case Report}

Pedro Hugo Bezerra Maia

Filho $^{l}$;

Bráulio Filgueira

Magalhães ${ }^{2}$;

George Wallisson Severo

de $S a^{3}$;

Whallyson Pinheiro

Mascarenha

\begin{abstract}
Hirschsprung's disease is a pathology characterized by the absence of ganglion cells in a variable segment of the large intestine, producing mainly the symptom of constipation and is usually diagnosed until the first year of life. We report the case of a young adult patient diagnosed at 18 years old with Hirschsprung disease with symptoms of constipation and involuntary fecal loss since the age of 5 years and who underwent videolaparoscopic surgical treatment by the Duhamel-Haddad technique, evolving with significant improvement in postoperative symptoms. This result demonstrates that the videolaparoscopic technique is feasible.
\end{abstract}

Keywords: Hirschsprung's disease; Megacolon Aganglionic; Constipation; Laparoscopy; Penetrating wound.

\section{Doença de Hirschsprung em um adulto jovem e seu tratamento com auxílio da Videolaparoscopia: Relato de Caso}

\begin{abstract}
Resumo: A Doença de Hirschsprung é uma patologia caracterizada pela ausência de células ganglionares em um segmento variável do intestino grosso, produzindo principalmente o sintoma de constipação, sendo normalmente diagnosticado até o primeiro ano de vida. Relatamos o caso de um paciente adulto jovem diagnosticado aos 18 anos com Doença de Hirschsprung com sintomas de constipação e perda fecal involuntária desde os 5 anos de idade e que foi submetido à tratamento cirúrgico videolaparoscópico pela técnica de Duhamel-Haddad em dois tempos, evoluindo com melhora importante dos sintomas no pós operatório. Tal resultado demonstra que a técnica videolaparoscópica é factível.
\end{abstract}

Descritores: Doença de Hirschsprung; Megacolon Agangliônico; Constipação; Laparoscopia; Penetrating wound.

\footnotetext{
${ }^{1}$ Graduado em Medicina pela Universidade Federal do Ceará. Residência Médica em Cirurgia geral pela Faculdade de Medicina de Juazeiro do Norte. Pós-Graduação latu sensu em Cirurgia Minimamente Invasiva e Robótica pela UNICHRISTUS;

${ }^{2}$ Graduação em Medicina pela Faculdade de Medicina Estácio de Juazeiro do Norte, Brasil;

${ }^{3}$ Graduação em Medicina pela Universidade Federal do Cariri - Campus Barbalha (UFCA), com ênfase em Saúde Pública, Emergências Cirúrgicas e Clínicas. Possui formação complementar em Suporte Avançado de vida Cardiovascular (ACLS) pela American Heart Association;

${ }^{4}$ Graduação em Medicina pela Faculdade de Medicina de Juazeiro do Norte.

Correspondências para: pedroed1913@ hotmail.com.
} 


\section{Introdução}

A doença de Hirschsprung (DH) também conhecido como megacolon agangliônico congênito, é uma anomalia caracterizada pela ausência de células ganglionares no plexo mioentérico e submucoso em um segmento variável do intestino (Kumar, 2010; Paz; Gonzalo; Gloria ,2008).

A ausência de células ganglionares resulta em contração permanente do segmento afetado, impedindo a passagem do conteúdo fecal por essa região (Kumar, 2010). A obstrução funcional distal leva a contrações peristálticas ineficientes, com consequente dilatação do intestino proximal, produzindo megacólon.

A DH apresenta-se com sintomas de constipação, atraso na eliminação do mecônio maior que 48h, distensão abdominal e vômitos. Em $80 \%$ dos casos a doença é diagnosticada no primeiro ano de da, sendo incomum na idade adulta; esses casos geralmente aparecem na forma de uma doença de segmento ultracurto (Icaza Chávez, et al., 2000).

É uma anomalia congênita que ocorre devido à interrupção da migração crâniocaudal das células da crista neural, responsáveis pela inervação do cólon ou quando as células ganglionares sofrem morte prematura entre a quinta e a $12^{\mathrm{a}}$ semana de gravidez (Kumar, 2010), Também foi sugerido que alterações na matriz extracelular no intestino humano podem interromper a migração de células derivadas da crista neural, produzindo aganglionose.

O objetivo deste trabalho é reportar um caso de DH em um jovem de 18 anos e seu tratamento cirúrgico por via laparoscopica no Hospital Geral Cesar Casls-HGCC, em Fortaleza -CE. A baixa frequência desse diagnóstico nessa idade e o curso clínico desse paciente ressaltam a singularidade deste caso.

\section{Relato de Caso}

Paciente do sexo masculino, 18 anos, caucasiano, que desde os 5 anos de idade apresentava tenesmo, constipação e distensão abdominal, chegando a passar 21 dias sem evacuar. Além disso apresentava episódios de perda fecal involuntária e quando evacuava 
era em pequenas quantidades e com grande esforço. Fazia uso crônico de laxantes orais sem sucesso terapêutico.

Procurou serviço de coloproctologia do HGCC já com exames laboratoriais, solicitados em outro serviço, tais como sorologia para doença de Chagas IGM e IGG ambos negativos, enema opaco evidenciando trânsito retrogrado do intestino grosso sem obstáculos mecânicos, cólons de calibre, relevo mucoso e elasticidade parietal normais, ausência de lesões vegetantes ou infiltrantes dos cólons, retosigmoide redundante (imagem 1) compatível com constipado crônico.

Imagem 1 - Enema opaco mostrando redundância dos cólons, Fortaleza-CE, 2019.

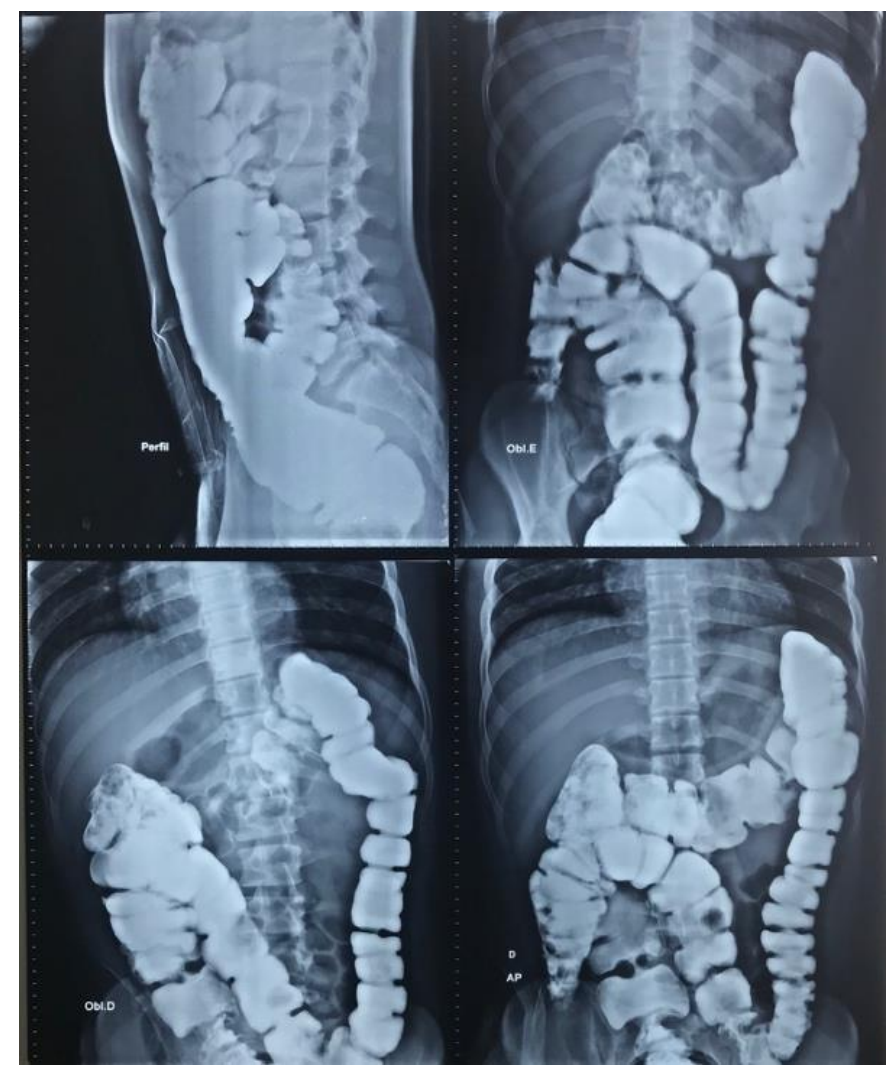

Fonte: Próprios autores, 2019.

Havia realizado também biopsia retal que mostrava ausência de células ganglionares, exame este que definiu a etiologia e o diagnostico final deste doente. Paciente refere não possuir alergias, cirurgias previas, hemotransfusões ou quaisquer outras patologias. Nega casos semelhantes, história de câncer ou outras patologias associadas na 
família. Refere ser ex- tabagista, ex-etilista e ex-usuário de drogas (maconha) tendo parado há três anos.

A proposta de tratamento cirúrgico foi cirurgia de Duhamel-haddad videolaparoscopica a qual foi submetido sem intercorrências em dois tempos. O primeiro tempo foi de abaixamento do cólon para ressecção do segmento agangliônico que foi direcionado à região perineal através de um túnel confeccionado no espaço retro-retal (imagem 2) até sua exteriorização por uma incisão na transição cutâneo mucosa anal e fixação para posterior anastomose definitiva. $\mathrm{O}$ excesso de cólon doente foi retirado neste tempo cirúrgico.

Imagem 2 - Dissecção do espaço retro-retal, Fortaleza-CE, 2019.

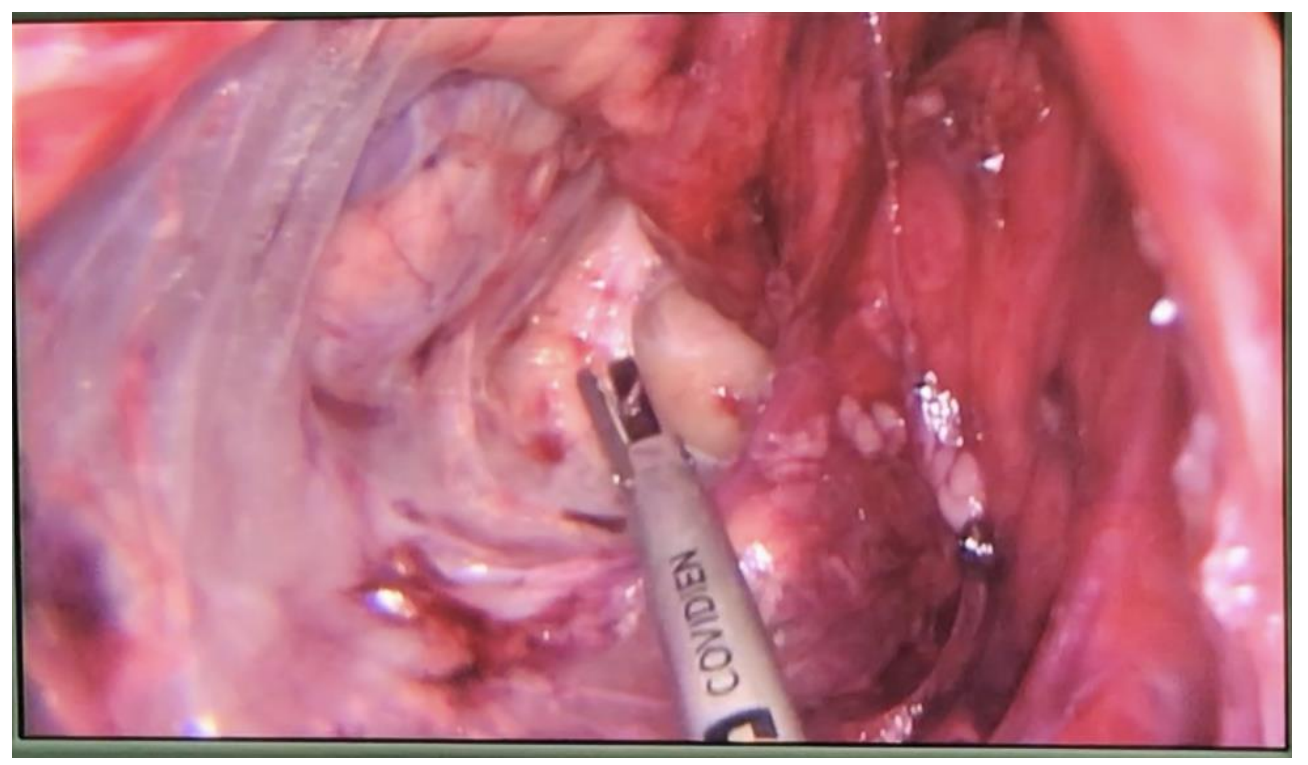

Fonte: Próprios autores, 2019.

Após 7 dias da primeira abordagem foi submetido a uma nova cirurgia, agora, para confecção da anastomose definitiva entre o cólon sadio e o reto/ânus .No terceiro dia pósoperatório foi reintroduzida dieta oral e progredida sequencialmente com boa aceitação até que no decimo quarto dia de internação (sétimo dia pós-operatório da segunda abordagem) recebeu alta hospitalar em bom estado geral e apresentando evacuações fisiológicas. Após trinta dias da alta retorna ao ambulatório de coloproctologia, referindo frequência de três evacuações diárias e um bom controle esfincteriano, mostrando-se satisfeito com a terapêutica utilizada. 


\section{Técnica Cirúrgica}

Após anestesia geral, paciente foi colocado em posição de Lloyd-Davis e Trendelemburg com lateral direita, para facilitar o deslocamento das alças intestinais da região a ser operada.

\section{Tempo abdominal}

O pneumoperitoneo foi realizado pela técnica fechada. Foram empregados cinco trocartes, dois de $10 \mathrm{~mm}$ (um na cicatriz umbilical e outro em fossa ilíaca direita) e três de $5 \mathrm{~mm}$ (um na fossa ilíaca esquerda e mais um em cada hipocôndrio) (imagem 3).

Imagem 3 - posicionamento dos trocarteres, Fortaleza-CE, 2019.

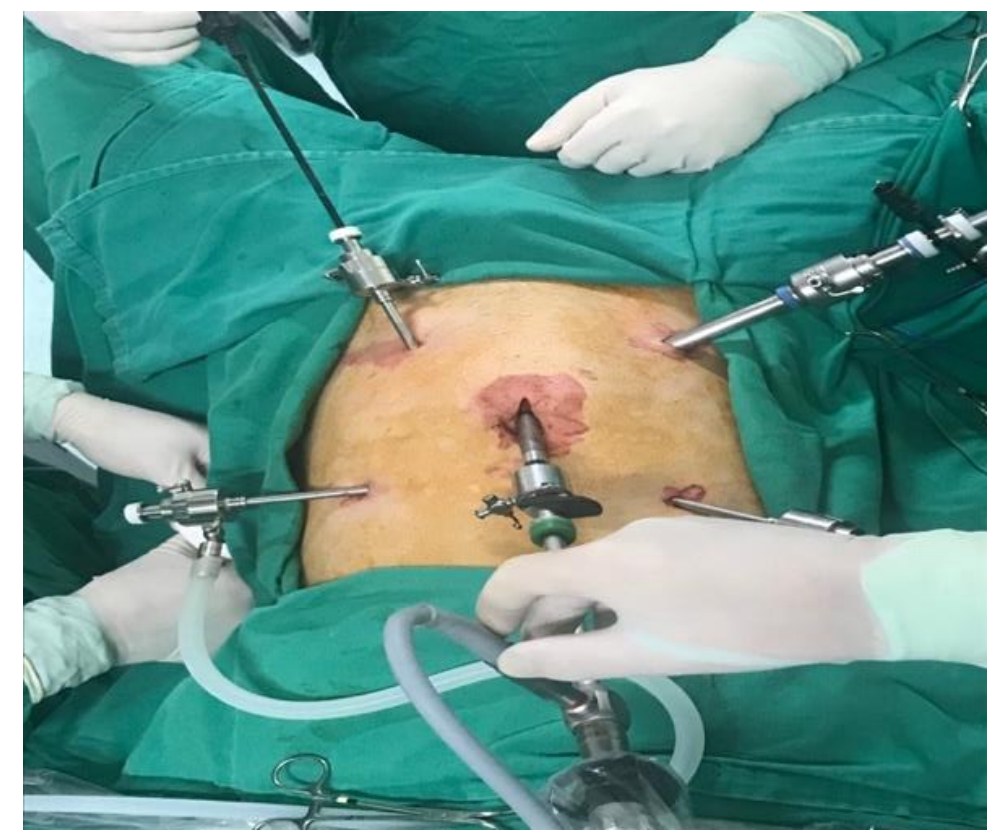

Fonte: Próprios autores, 2019.

Para facilitar a dissecção as mesas são colocadas em Trendelemburg e decúbito lateral direito. O primeiro passo, após passagem de todos os trocaters, é a exposição do ângulo de Treitz com identificação de veia e artéria mesentéricas inferiores (VMI e AMI). 
O abaixamento do ângulo esplênico do cólon foi realizado após a ligadura da VMI e da AMI, através de identificação do plano avascular entre o cólon e o retroperitônio. A identificação da artéria retal superior foi realizada através da dissecção da AMI concluindo sua ligadura. A dissecção correta do plano, neste momento, leva a identificação do ureter e dos vasos gonadais.

Prossegue-se com a dissecção do espaço retrorretal (imagem 2) até o nível dos elevadores. O peritônio à direita, é aberto até a reflexão peritoneal. Concluída a liberação da goteira parieto-cólica esquerda, foi iniciada a abertura da reflexão peritoneal anterior, sendo possível identificar as vesículas seminais. Após medida do coto retal, determina-se o ponto de secção do reto, devendo restar aproximadamente $8.0 \mathrm{~cm}$ de coto retal.

O ponto de secção do reto foi preparado através da ligadura do mesoreto com bisturi Ultracision e a secção concluída com endogrampeador (imagem 4).

Imagem 4 - secção do cólon sigmoide com endogrampeador linear, Fortaleza-CE, 2019.

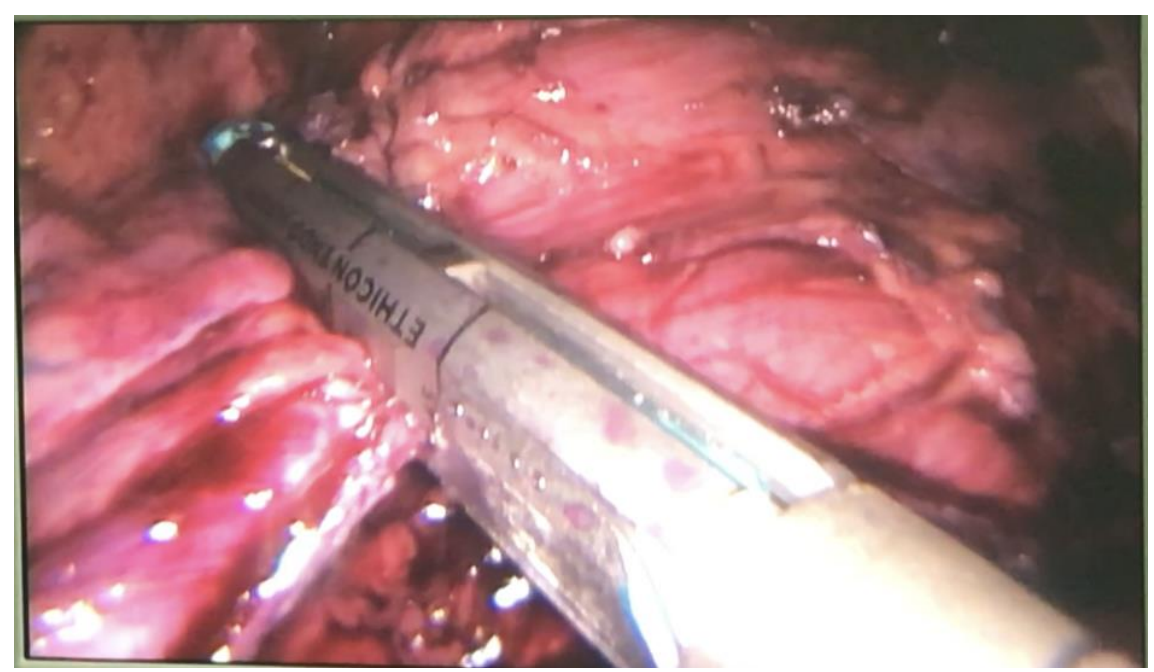

Fonte: Próprios autores, 2019.

\section{Tempo Perineal}

Expõe-se o reto e o ponto de transição cutâneo-mucosa com pontos de tração radiais, infiltra-se com solução de adrenalina 1/200.000. Determinando a linha de incisão entre $1 \mathrm{a} 2 \mathrm{~cm}$ acima da linha pectínea. Disseca-se o plano interesfincteriano até ultrapassar 
o nível dos elevadores onde se encontra o reto preparado previamente por via laparoscópica.

Através da incisão posterior no reto avança-se uma pinça de Duval na cavidade pélvica sob visão da câmera, apreende-se a extremidade seccionada do reto e traciona-se a peça através da incisão cutânea afim de fixa-la. O excesso de cólon é então seccionado para que possamos, posteriormente, realizar a anastomose definitiva apresentando menor taxa de deiscência (imagem 5).

Imagem 5 - aspecto final do tempo perineal antes e após remoção do segmento aganglionico, Fortaleza-CE, 2019.

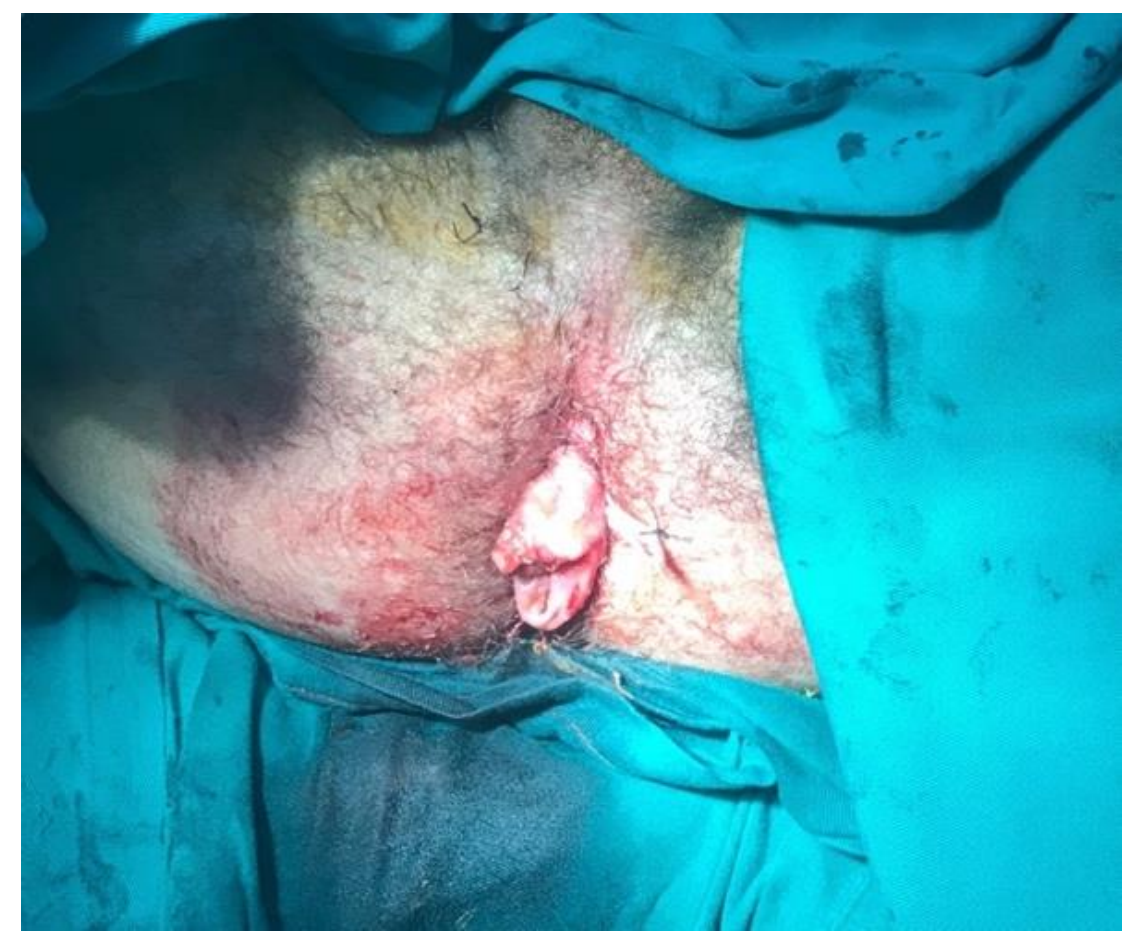

Fonte: Próprio autores, 2019.

No $7^{\circ}$ PO foi realizada a anastomose definitiva utilizando-se de um grampeador linear para a anastomose entre a parede posterior do reto e o bordo anterior do cólon e sutura manual com caprofil 3.0 para anastomose entre o bordo posterior do cólon e a borda anal( imagem 6). 
Imagem 6 - aspecto final após anastomose definitiva com bordo anal, Fortaleza-CE, 2019.

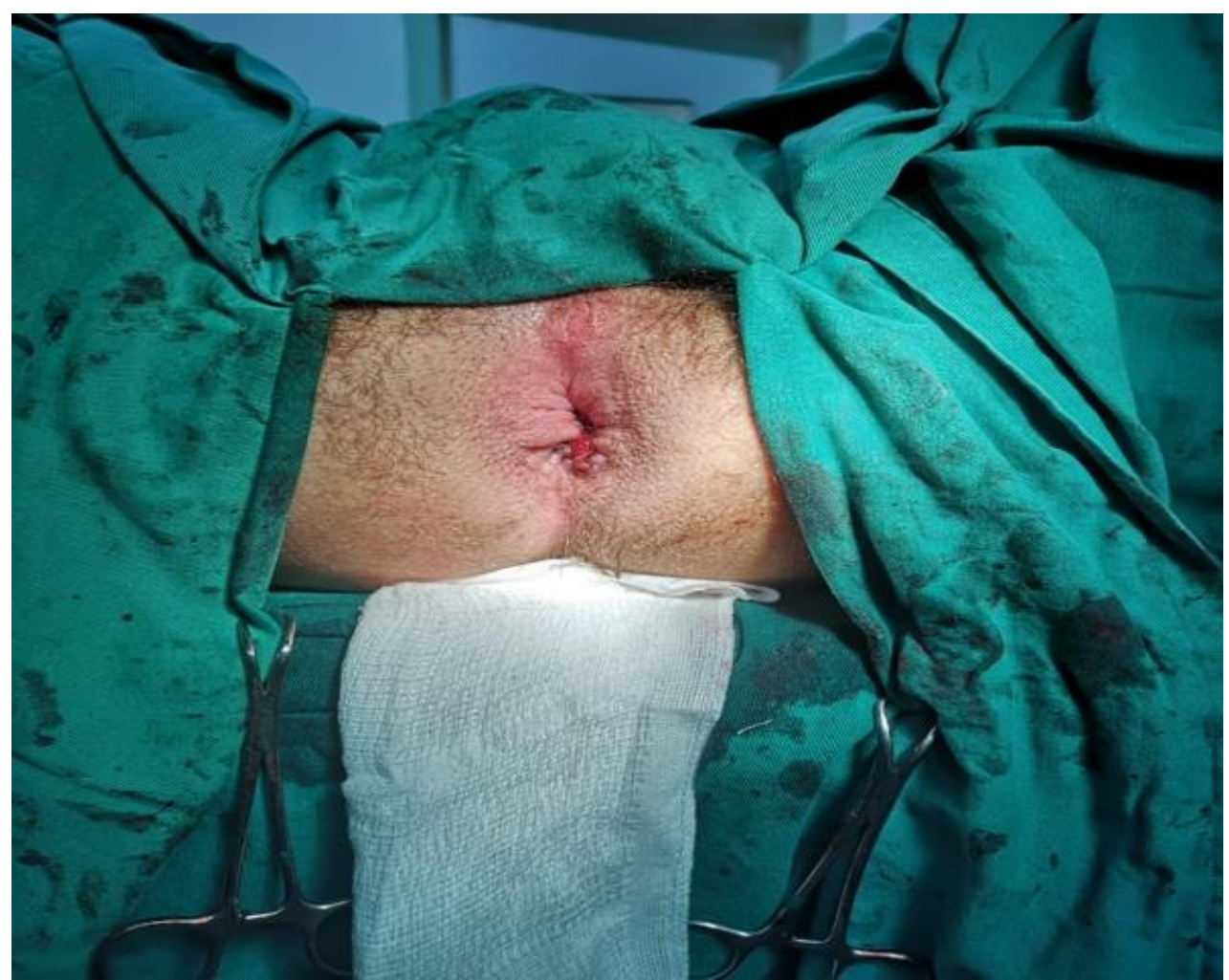

Fonte: Próprios autores, 2019.

\section{Discussão}

Em relação à apresentação clínica do paciente, o quadro insidioso de constipação dificultou o diagnóstico precoce retardando o tratamento até a idade adulta.

Dentre as principais complicações cirúrgicas a possibilidade de necrose do cólon abaixado, deiscência de anastomose e abscessos pélvicos desencorajou a muitos cirurgiões no início da técnica. As variações introduzidas com a anastomose colo-retal em dois tempos foram benéficas na redução da incidência de abscessos e permitiram o diagnóstico precoce da necrose fazendo com que essa técnica se firmasse como padrão no tratamento da DH (Haddad; Raia,1969).

A utilização da via laparoscópica implicou em melhor resultado estético, menor morbidade pós-operatória, não houve complicações de feridas houve menor tempo de internação e retorno precoce as atividades do paciente em questão. 
Quanto à continência fecal após anastomose colo-retal, dados da literatura mostram que ocorre incontinência temporária para gases e líquidos, com reversão completa dos sintomas após 4 meses (Pedroso et al., 2003). Até o momento nosso paciente não havia apresentado tais sintomas.

De acordo com a extensão do envolvimento do cólon, a DH é classificada em doença de segmento curto ( $80 \%$ dos casos), quando o segmento aglionglionar não excede o cólon sigmóide; ou em doença de segmento longo, quando ultrapassa o cólon sigmóide. Nesse último caso, a DH pode afetar todo o cólon e até o intestino delgado(Villar et al., 2009).

A DH ainda é classificada na doença do segmento ultracurto quando envolve apenas a parte distal do reto, ocorrendo em 2-3\% (em alguns relatos, com estimativas de até 8\%) dos casos (Bakari et al., 2011; Paz; Gonzalo; Gloria, 2008).

A DH ocorre em aproximadamente 1 em cada 5.000 nascidos vivos. Pode ocorrer isoladamente ou em combinação com outras anormalidades do desenvolvimento; $10 \%$ de todos os casos ocorrem em crianças com síndrome de Down.

A maioria dos casos de DH é esporádica, mas $10 \%$ têm origem familiar. Metade dos casos familiares e $15 \%$ dos casos esporádicos estão associados a mutações gênicas que inativam o receptor RET da tirosina quinase no cromossomo 10q. Alguns casos envolvem mutações genéticas para o receptor da endotelina-B.3 Como esse é um distúrbio autosomico dominante com penetrância incompleta, a mutação de genes ou fatores ambientais também devem ter importancia(Kumar, 2010)

Além disso, estabelece-se que fatores relacionados ao gênero desempenham um papel, uma vez que os homens são afetados preferencialmente, com uma frequência de 4: 1,5. No entanto, nos casos em que o diagnóstico é feito em uma idade mais avançada, a frequência é maior entre as mulheres (3:1) (Lombana; Domínguez, 2007). O que difere do caso do nosso paciente.

Os sintomas que levam a uma suspeita precoce de DH são a constipação intestinal, definida no recém-nascido como um atraso superior a 48 horas na eliminação do mecônio associado à distensão abdominal e vômitos. Em 80\% dos casos, a DH é diagnosticada no primeiro ano de vida. Esse distúrbio é incomum na adolescência e na idade adulta e, quando presente nessa faixa etária, aparece como uma doença do segmento ultracurto(Icaza Chávez, 2000) 
Na literatura, em 50-60\% dos casos, o diagnóstico é estabelecido no primeiro mês de vida(Bigélli et al., 2002). No entanto, casos leves de HD podem dificultar um diagnóstico precoce, seja por falta de sintomas ou porque seus sintomas são mal interpretados. Nesses casos, é comum um certo grau de constipação de intensidade flutuante, com o fecaloma caracterizando a progressão clínica, frequentemente associada a alterações na nutrição e no cresciment(Jones; Godding, 1975)

Alguns pacientes atingem a idade adulta sem um diagnóstico para esta doença. Normalmente, os pacientes procuram um médico com uma história de constipação de longa data que requer uso frequente de laxante(Gordon, 1992). A frequência atual da doença em adultos é desconhecida, principalmente porque a DH é uma doença negligenciada e mal diagnosticada nessa faixa etária.

Nosso paciente tinha histórico de constipação intestinal de longa data, evoluindo para incontinência fecal. Esse achado pode ser explicado por uma distensão permanente do canal anal devido à presença de um fecaloma, com pressão constante no esfíncter interno e mantendo-o aberto. Portanto, as fezes mais líquidas a montante passam pela impactação fecal e produzem o sintoma relatado, conhecido como incontinência fecal (soiling). Este curso clínico é atípico; na revisão de literatura, apenas três casos semelhantes foram relacionados em associação à doença de Hirschsprung. (Barnes et al., 1986; Soto, 2001).

As queixas de incontinência fecal são frequentemente relatadas na literatura em casos de constipação funcional e megacólon idiopático(Motta, 2005;Gordon, 1992). Esse problema também é relatado em pacientes com megacólon adquirido, sendo mais incomum em casos congênitos devido à permanência de um esfíncter anal interno fechado (Gordon, 1992). A incontinência fecal é uma complicação pós-operatória comum do megacólon congênito(PAZ, 2000). Portanto, a incontinência fecal pode causar distúrbios emocionais aos pacientes, com subsequentes problemas de relacionamento na escola, trabalho e com a própria família(De Morais, 2000 ).

O diagnóstico de DH é apoiado por estudos de enema de bário, manometria anorretal e biópsia retal (Icaza Chávez, 20000

A técnica considerada como padrão-ouro para o diagnóstico de DH é a ausência de células ganglionares em uma amostra de biópsia retal. Além disso, pode haver um aumento das fibras nervosas colinérgicas não mielinizadas na submucosa e entre as camadas musculares (hiperplasia neural), o que ajuda na confirmação diagnóstica (Paz; Gonzalo; Gloria 2008). 
Estudos de imagem como tomografia computadorizada (TC) e enemas de bário são geralmente aceitos para avaliação da constipação crônica, que é um distúrbio comum em adultos (Carmo et al., 2015) Nosso paciente foi submetido a um enema de bário, método simples e barato em comparação com a tomografia computadorizada.

A manometria anorretal, apesar de não ter sido usada no presente caso, é um exame auxiliar de extrema importância, uma vez que a presença do reflexo reto-anal neste exame geralmente exclui o diagnóstico de DH (Motta, 2005).

Vários procedimentos são utilizados para gerenciar esta doença após a infância;

Atualmente, a opção de escolha é o procedimento cirúrgico de Duhamel. (Gordon 1992) O diagnóstico tardio contribui para a necessidade de cirurgia em mais de um tempo cirúrgico, com ileostomia ou colostomia, uma vez que o cólon saudável é mais distendido em adolescentes e adultos do que em neonatos e crianças' (Lombana; Domínguez, 2007).

No entanto, a literatura considera como procedimento de escolha a técnica de Duhamel em apenas um tempo cirúrgico (Paz; Gonzalo; Gloria, 2008) o que reduz o tempo de internação.

Esta cirurgia é considerada curativa. No entanto, o funcionamento intestinal pósoperatório nem sempre é satisfatório. Enterocolite, constipação e incontinência fecal representam as principais complicações pós-operatórias em crianças(Villar et al., 2009).

Até o momento, a progressão para pacientes adolescentes ou adultos ainda não está totalmente esclarecida, devido ao pequeno número de casos relatados.

\section{Conclusão}

Pode-se concluir que a técnica de Duhamel-Haddad videolaparascopica é factível, apresenta baixo índice de complicações peri-operatórias e melhor resultado estético pela manutenção da integridade da parede abdominal e retirada da peca por via perineal.

\section{Referências}

Bakari, AA. et al. (2011). Case report: congenital aganglionic megacolon in Nigerian adults: two case reports and review of the literature. Niger J Clin Pract. V. 14, p. 249-52.

Barnes, P. R. et al.(1986). Hirschsprung's disease and idiopathic megacolon in adults and adolescents. Gut, v. 27, n. 5, p. 534-541. 
Bigélli, Rosa HM et al.(2002). Estudo retrospectivo de 53 crianças com doença de Hirschsprung: achados clínicos e laboratoriais. Medicina (Ribeirão Preto. Online), v. 35, n. 1, p. $78-84$.

Carmo, Rafael LML et al. Trânsito intestinal em crianças e adolescentes com constipação crônica. Jornal de Pediatria, v. 91, n. 4, p. 386-391, 2015.

De Morais, Mauro Batista; Maffei, Helga Verena L. Constipação intestinal. J Pediatr, v. 76, n. 2, p. 147-156, 2000.

Gordon, P. H.(1992). NivatvongsS: Principles and Practices of Surgery for the Colon, Rectum, andAnus. Quality Medical Publishing, lnc, St. Louis, p. 1047-1048.

Haddad, J.; Raia, A.(1969). Complications of recto-colonic anastomosis using Swenson's and Duhamel's technics for the treatment of megacolon.(Comparative study). AMB: revista da Associacao Medica Brasileira, v. 15, n. 6, p. 265-270.

Icaza Chávez, M.E. et al. (2000). Enfermedad de Hirschsprung en el adulto. Informe de um caso. Rev Gastroenterol Méx, v. 65, p. 171-4.

Jones F.A.; Godding E.W. (1975). Tratamento da constipacao. São Paulo: Manole.

Kumar, Vinay.(2010) Robbins \& cotran-patologia bases patológicas das doenças 8a edição. Elsevier Brasil.

Lombana, Luis Jorge; Domínguez, Luis Carlos.(2007). Cirugía en la enfermedad de Hirschsprung del adulto. Rev Colomb Gastroenterol, v. 22, p. 231-7.

Motta, U. F. N. (2005). A Manometria Anorretal (Método do Balão) no Diagnóstico Diferencial da Doença de Hirschsprung. Rev Assoc Med Bras, v. 51, n. 6, p. 313-17.

Paz, A. M.; Gonzalo, A.; Gloria, R. C.(2008) Revisión: Enfermedad de Hirschsprung. Rev Ped Elec. v.5, n.1.

Pedroso, M. et al.(2003). Tratamento Laparoscópico do Megacólon Chagásico pela Técnica de Duhamel Modificada. Experiência de 30 Casos. Rev bras videocir, v. 1, n. 2, p. 55-9.

Soto, D. (2001). Enfermedad de Hirschsprung en adultos. Rev Cir Chil, v. 53, p. 346.

Villar, M.A.M. et al. (2009) Doença de Hirschsprung: experiência com uma série de 55 casos. Rev Bras Saúde Matern Infant. 3:285-91.

\section{How to cite this article (APA format):}

Maia Filho, Pedro Hugo Bezerra; Magalhães, Bráulio Filgueira; Sá, George Wallisson Severo de; Mascarenha, Whallyson Pinheiro (2020). Hirschsprung's Disease in a young adult and its treatment with Videolaparoscopy Aid: Case Report. Am. In. Mult. J., February to May. (8) 5, $7-18$.

Received: 01/14/2020;

Accepted: 01/17/2020. 